\title{
Mitochondrial Membrane Protein-associated Neurodegeneration: Two Adult Cases with Different Clinical Presentation
}

\author{
Mitokondriyal Membran Protein-ilişkili Nörodejenerasyon; Farklı Klinik Prezentasyonlu
} Íki Yetişkin Olgu

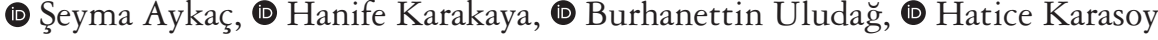 \\ Ege University Faculty of Medicine, Department of Neurology, Izmir, Turkey
}

\begin{abstract}
Neurodegeneration with brain iron accumulation is a clinically and genetically heterogeneous group of diseases. Mitochondrial membrane protein-associated neurodegeneration is a rare subtype of this disease spectrum. Thus, this case report aimed to draw attention to this rarely seen disease.
\end{abstract}

Keywords: Mitochondrial membrane protein, iron deposition, neurodegeneration

$\ddot{\mathbf{O z}}$

Beyin demir birikimiyle gelişen nörodejenerasyon, klinik ve genetik olarak heterojen bir hastalık grubudur. Mitokondriyel membran protein-ilişkili nörodejenerasyon bu hastalık spektrumunun nadir görülen bir subtipidir. Bu olgu sunumuyla, nadir görülen bu hastalığa dikkat çekmek istedik.

Anahtar Kelimeler: Mitokondriyel membran protein, demir birikimi, nörodejenerasyon

\section{Introduction}

Neurodegeneration with brain iron accumulation (NBIA) is a clinically and genetically heterogeneous group of neurodegenerative diseases, the majority of which is hallmarked by iron deposits in the brain (1). Iron accumulation is detected mainly in the globus pallidus (GP) and the substantia nigra (SN), with the involvement of the cortex and the cerebellum. These disorders are inherited as Mendelian traits (autosomal recessive, dominant, or X-linked), and typical features include extrapyramidal symptoms, such as dystonia, Parkinsonism, spasticity, variably associated with neuropsychiatric abnormalities, and optic atrophy or retinal degeneration (1). The presence of brain iron accumulation enables the diseases to be included in the NBIA group, but the pathogenic mechanisms linking specific disease-genes mutations to iron metabolism are unclear. The most common NBIA type is pantothenate kinase-associated neurodegeneration (PKAN) and mitochondrial membrane protein-associated neurodegeneration (MPAN), which accounts for $5-30 \%$ of all NBIA types (2). Herein, presented are cases of two adults with a different clinical presentation that were diagnosed as MPAN to draw attention to this rarely seen disease.

\section{Case Reports}

Case 1

A 29-year-old male patient presented with suicidal thinking, auditory hallucinations, withdrawal from friends, slowing of movements, trembling of the hands, and stiffness of the extremities. His symptoms began 2 years ago, with progressive worsening. The case, which was followed by the diagnosis of schizophrenia in the psychiatric clinic, was referred to our clinic to investigate possible organic causes. The parents were consanguineous and without a family history of neurologic and psychiatric disease. His neurological examination revealed bradymimia, bradykinesia, rigidity on the axial and extremity muscles, and postural and actional tremors on both hands. Bilateral interosseal atrophy and fasciculations on extremity muscles were also detected without overt muscle strength loss. Moreover, the deep tendon

Address for Correspondence/Yazışma Adresi: Şeyma Aykaç MD, Ege University Faculty of Medicine, Department of Neurology, Izmir, Turkey Phone: +90 5304153692 E-mail: symaykac@gmail.com ORCID: orcid.org/0000-0003-3994-0019

Received/Geliş Tarihi: 08.01.2021 Accepted/Kabul Tarihi: 16.05.2021

${ }^{\circ}$ Copyright 2021 by Turkish Neurological Society

Turkish Journal of Neurology published by Galenos Publishing House. 
reflexes were hypoactive in the upper and lower extremities. Brain magnetic resonance imaging (MRI) showed symmetric hypointensity of the bilateral GP and SN in the T2-WI and fluidattenuated inversion recovery (FLAIR) with hyperintensity of the same brain sites in T1-WI (Figure 1). MRI findings suggested NBIA spectrum disease, and laboratory tests, liver and kidney function tests, serum electrolytes and ammonia, hemogram, serum ceruloplasmin, iron, transferrin, and $24 \mathrm{~h}$ urine copper, which were performed to exclude systemic causes, were within normal limits. Genetic analysis was then performed to identify the disease type of the NBIA spectrum. In the genetic test, homozygote c.32C>T (p.Thr11 Met) mutation was detected in the C19orf12 gene and the patient was diagnosed as MPAN. Other subclinical neurological involvements were examined because of the disease process. Optic atrophy was not seen. Electroneuromyography (EMG) revealed normal nerve conduction studies, but low amplitude compound muscle action potentials (CMAP) were detected on the upper and lower extremity distal muscles. The needle EMG revealed that diffuse denervation and neurogenic motor unite potential (MUPs) on proximal and distal limb muscles were supporting widespread anterior horn cell involvement.

\section{Case 2}

An 18-year-old male patient presented with complaints of difficulty in getting up from his seat and walking, and impaired speech starting at the age of 10 years. The parents were consanguineous, with similar complaints in his 7-year-old brother. The neurological examination revealed mild mental retardation, dysarthria, lower extremity proximal muscle weakness (3-4/5 muscle power) with prominent spasticity, and bilateral Babinski sign. Brain MRI on T2WI and FLAIR (Figure 2) showed bilateral hypointensity in the SN and GP with a streak of hyperintensity in the medial medullary lamina (GP splitting). Laboratory tests, liver and renal function tests, serum electrolytes and creatine kinase-myoglobin levels, hemogram, serum ceruloplasmin, iron, transferrin, and $24 \mathrm{~h}$ urine copper were all normal. EMG was performed due to proximal muscle weakness. Conduction velocities were normal in nerve conduction studies in EMG; however, decreased motor nerve CMAP amplitudes and diffuse denervation and neurogenic MUP changes were observed in the needle EMG. Therefore, widespread anterior horn motor neuron involvement was considered. When evaluated together with progressive motor symptoms, dysarthria, spastic paraparesis, cognitive symptoms, family history, and cranial MRI findings, the patient was thought to have NBIA spectrum disorder, thus genetic testing was requested. The genetic test revealed homozygote p.Gly69ArgfsX10 mutations in the C19orf12 gene and the patient was diagnosed as MPAN. The same mutation was also observed in his 7-year-old brother who had similar clinical symptoms.

\section{Discussion}

NBIA is a group of rare diseases characterized by iron deposition in the brain. Mutations in the C19orf12 cause autosomal recessive inherited MPAN that was firstly described in Polish patients (1). The mean age at onset of MPAN is 10 years, and cases have been reported between 3 and 30 years of age (2). The clinical symptoms associated are prominent Parkinsonism, pyramidal signs, psychiatric disturbances, cognitive decline, and motor axonal neuropathy in various combinations. The most common

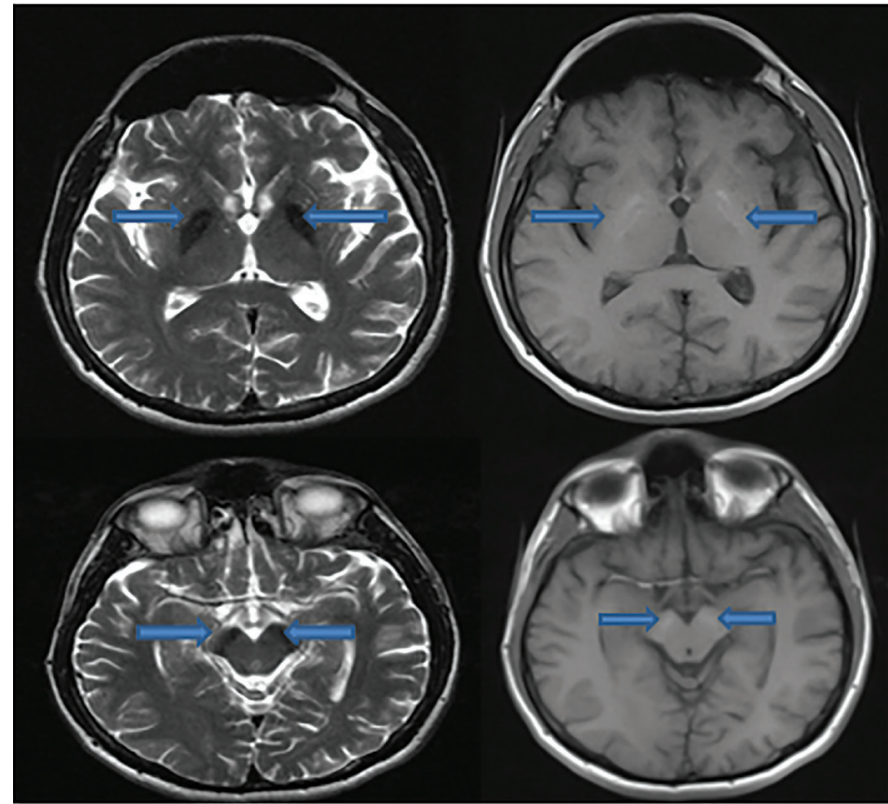

Figure 1. Bilateral hypointensity of globus pallidus and substantia nigra in T2-weighted images on the left column and hyperintensity of the same sites in T1-weighted images on the right column (blue arrows)

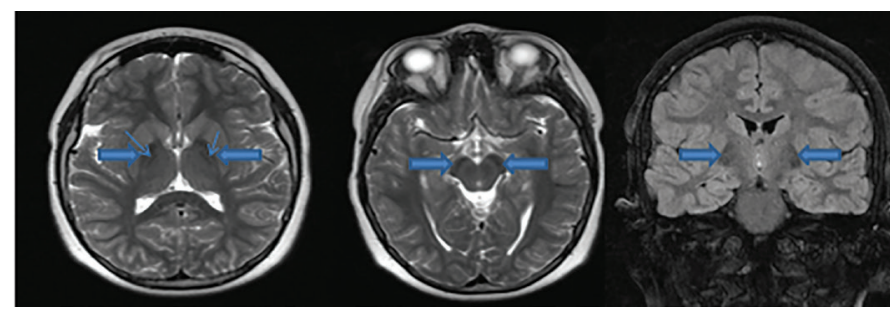

Figure 2. Bilateral hypointensity in the substantia nigra and the globus pallidus on T2WI and FLAIR sequences of cranial MRI (from left to right, thick blue arrows) with a streak of hyperintensity in the medial medullary lamina (globus pallidus splitting) (thin blue arrows)

FLAIR: Fluid-attenuated inversion recovery, MRI: Magnetic resonance imaging

neurologic feature was upper motor neuron lesion manifesting as spasticity, hyperreflexia, and/or Babinski sign in $82 \%$ of patients (1), whereas motor neuropathy manifesting as limb weakness, fasciculations, and atrophy was present in $41 \%$ of patients (1). From extrapyramidal signs, the most common abnormality was dystonia, particularly in the lower limbs in $53 \%$ of patients. Parkinsonism and tremors were present in $43 \%$ and $14 \%$ of patients, respectively. Parkinsonism and dystonia occur in older patients and/or in patients with a longer duration of symptoms, their prevalence may thus increase with disease progression (3). The frequencies of psychiatric symptoms and dementia in MPAN were $47 \%$ and $57 \%$, respectively (1).

The responsible gene for the disease is C19orf12, a protein localized to the mitochondria and endoplasmic reticulum, mutations of which cause disruption of lipid homeostasis in the mitochondria 
(2). The literature described 35 pathogenic mutations in the C19orf12 gene and the two most common are p.Gly69ArgfsX10 and p.Thr11Met (1). The C19orf12 p.Thr11Met mutation is most commonly detected in adult Turkish patients with MPAN. The clinical phenotype is characterized by adult-onset in most cases (mean 24.5 years) and broad-spectrum clinical presentation is seen as prominent Parkinsonism, pyramidal signs, psychiatric disturbances, cognitive decline, and motor axonal neuropathy in various combinations (4). The p.Gly69ArgfsX10 mutation of MPAN was reported by Skowronska et al. (5) in a study that included a series of patients from Poland. This study revealed that the age at onset was usually in childhood and generally starting with gait disorder and visual loss due to optic atrophy, followed by spastic para- or tetraparesis with muscle atrophy. Patients with MPAN and homozygous p.Thr11Met were compared with homozygous p.Gly69ArgfsX10 mutations, which found several evident differences in the clinical presentation. MPAN caused by p.Thr11Met mutations had later onset, and optic atrophy is much less frequent and Parkinsonism is more common. Psychiatric signs may also be more common in carriers of the p.Thr11Met mutant (6).

Brain MRI of MPAN cases shows iron accumulation in the $\mathrm{SN}$ and GP on T2 and gradient-echo sequences. Furthermore, some patients have hyperintense streaking of the medial medullary lamina between the GP interna and externa (GP splitting). Cortical and cerebellar atrophy may be seen in advanced disease (7).

Similar to other NBIA, curative treatment is unavailable and the patient management relies on rehabilitation and symptomatic medications, such as anti-spastic agents, anticholinergics, dopaminergic agents, and botulinum toxin.

Clinical phenotypes and imaging findings are helpful to differentiate MPAN from other types of NBIA disorders. The onset of clinical symptoms is in later age onset and milder compared with PKAN (8). In addition, the T2-weighted-MRI images displayed bilateral hypointensities in the GP and SN all patients, without an eye-of-the-tiger sign (8). Homozygous inheritance of mutant C19orf12 is also linked to Behr syndrome, hereditary spastic paraplegia type 43, and juvenile-onset amyotrophic lateral sclerosis (ALS) (7). Apart from juvenile ALS, classical cranial MRI findings related to MPAN are not seen in Behr syndrome and hereditary spastic paraplegia (9).

Our first case had psychiatric disturbances with clinical findings of Parkinsonism, and the disease onset was later compared with the second case. His cranial MRI findings supported the diagnosis of MPAN by demonstrating bilateral hypointensities in the GP and SN on T2 weighted images without the eye-ofthe-tiger sign. We did not detect any pyramidal signs in the neurological examination. Apart from axonal motor neuropathy, EMG supported widespread anterior horn cell involvement. As reported in the literature, homozygous p.Thr11Met mutation, in this case, was compatible with disease onset and predominant extrapyramidal findings. The second case was presented with the common clinical neurologic feature of MPAN as progressive spastic paraparesis. The disease onset was earlier and compatible with homozygous mutation p.Gly69ArgfsX10 in the reported cases. Cranial MR findings and his family history were important clues for the diagnosis. In addition, an anterior horn cell involvement was also detected on the EMG. Thus, apart from motor axonal neuropathy, our cases had anterior horn cell disease. Especially, the second case was mimicking juvenile ALS. However, cranial MRI findings and additional neurological findings pointed out MPAN. Due to curative treatment unavailability, symptomatic medications in both of our patients were used with rehabilitation.

Therefore, MPAN is a rare subtype of NBIA spectrum disorders. Neurological symptoms usually resemble each other in these spectrum disorders; however, cranial MRI findings and genetic tests must be considered to make the correct diagnosis.

\section{Ethics}

Informed Consent: Written consent was obtained.

Peer-review: Externally peer-reviewed.

\section{Authorship Contributions}

Surgical and Medical Practices: B.U., H.Karasoy, Concept: Ş.A., Design: Ş.A., Data Collection or Processing: Ş.A., H.Karakaya, Analysis or Interpretation: Ş.A., B.U., H.Karasoy, Literature Search: Ş.A., H.Karakaya, Writing: Ş.A.

Conflict of Interest: No conflict of interest was declared by the authors.

Financial Disclosure: The authors declared that this study received no financial support.

\section{References}

1. Dusek P, Skoloudik D, Roth J, et al. Mitochondrial membrane proteinassociated neurodegeneration: a case report and literature review. Neurocase 2018;24:161-165.

2. Gregory A, Hayflick S. Neurodegeneration with brain iron accumulation disorders overview. In: Pagon RA, Adam MP, Ardinger HH, et al, (eds). GeneReviews(R). Seattle: University of Washington, 2014.

3. Selikhova M, Fedotova E, Wiethoff S, et al. A 30-year history of MPAN case from Russia. Clin Neurol Neurosurg 2017;159:111-113.

4. Olgiati S, Doğu O, Tufekcioglu Z, et al. The p.Thr11Met mutation in c19orf12 is frequent among adult Turkish patients with MPAN. Parkinsonism Relat Disord 2017;39:64-70.

5. Skowronska M, Kmiec T, Jurkiewicz E, et al. Evolution and novel radiological changes of neurodegeneration associated with mutations in C19orf12. Parkinsonism Relat Disord 2017;39:71-76.

6. Deutschländer A, Konno T, Ross OA. Mitochondrial membrane proteinassociated neurodegeneration. Parkinsonism Relat Disord 2017;39:1-3.

7. Kruer MC, Boddaert N, Schneider SA, et al. Neuroimaging features of neurodegeneration with brain iron accumulation. AJNR Am J Neuroradiol 2012;33:407-414.

8. Hayflick SJ, Westaway SK, Levinson B, et al. Genetic, clinical, and radiographic delineation of Hallervorden-Spatz syndrome. N Engl J Med 2003;348:33-40.

9. Kim J, Liao YH, Ionita C, et al. Mitochondrial Membrane ProteinAssociated Neurodegeneration Mimicking Juvenile Amyotrophic Lateral Sclerosis. Pediatr Neurol 2016;64:83-86. 